\title{
Comunicação
}

[Communication]

\section{Microbiota bacteriana em segmentos de mosca do estábulo Stomoxys calcitrans no Brasil: primeiro relato de espécies}

\author{
[Microbiota in Stomoxys calcitrans segments in Brazil: First description of species] \\ B.G. Castro $^{1}$, M.M.S. Souza ${ }^{2}$; A.J. Bittencourt ${ }^{3}$ \\ ${ }^{1}$ Aluno de pós-graduação CPGCV - UFRRJ - Seropédica, RJ \\ BR 465, Km 7 \\ ${ }^{2}$ Departamento de Microbiologia e Imunologia Veterinária - UFRRJ - Seropédica, RJ \\ ${ }^{3}$ Departamento de Medicina e Cirurgia Veterinária - UFRRJ - Seropédica, RJ
}

Diferentes espécies de muscídeos têm potencial de veiculação de mais de 100 microrganismos patogênicos, que estão associados a mais de 65 enfermidades humanas e animais (Förster et al., 2007). Dentre estes muscídeos, a mosca do estábulo, Stomoxys calcitrans, destaca-se pelo hematofagismo e pela capacidade de veicular agentes patogênicos, (Greenberg, 1971; Foil et al., 1983; Kerr, 2002; Castro, 2004; Banjo, 2005). Mesmo assim, os estudos que concernem à veiculação e transmissão de agentes patogênicos pela mosca do estábulo no Brasil são bastante escassos. De acordo com Greenberg (1971), 47 espécies bacterianas podem ser veiculadas pela mosca do estábulo. Segundo o autor, na mosca doméstica Musca domestica (Diptera: Muscidae), haviam sido verificadas, aproximadamente, 200 espécies e subespécies bacterianas. Isso possivelmente se explica pelo fato de a mosca doméstica Musca domestica apresentar maior sinantropismo e alto potencial biótico, quando comparada à mosca do estábulo.

Esta comunicação teve por objetivo relatar espécies bacterianas isoladas em segmentos de mosca do estábulo, no Brasil. Para tal, foram visitadas 20 propriedades rurais leiteiras. Coletou-se, com o auxílio de um puçá entomológico previamente desinfetado, uma espécie em cada propriedade. A coleta ocorreu a uma distância máxima de $50 \mathrm{~cm}$ dos animais, como recomendado por Bramley (1985).
As moscas do estábulo, identificadas de acordo com Furman e Catts (1982), colhidas em tubos de ensaio e mortas por congelamento a $-10^{\circ} \mathrm{C}$ foram colocadas em tubos contendo caldo infuso cérebro coração (BHI). Esse meio foi selecionado por ser enriquecido, o que favorece o crescimento de todos os tipos bacterianos. Após agitação, as moscas foram transferidas para outro tubo com álcool $70 \%$, onde permaneceram por dois minutos, para esterilização de sua superfície externa, de acordo com a descrição de Hillerton e Bramley (1985).

Sob a luz de um microscópio estereoscópio, cada mosca foi colocada em uma placa de Petri estéril invertida, para separação entre cabeça e tórax, observando-se naquela basicamente três estruturas unidas: cabeça, probóscida e glândulas salivares. Esse conjunto, transferido a um outro tubo contendo caldo BHI, foi macerado com auxílio de um bastão de vidro estéril.

Posteriormente, cada mosca foi colocada em uma nova placa de Petri invertida para separação entre abdome e tórax e conseqüente retirada da porção abdominal do tubo digestório (Oliveira et al., 2002)

Cada amostra foi incubada a $37^{\circ} \mathrm{C}$ por 24 horas e, posteriormente, repicada pelo método de esgotamento por estria, em placas de ágares BHI, 
MacConkey (AMC) e manitol vermelho de fenol (AMVF). As placas foram novamente incubadas a $37^{\circ} \mathrm{C}$ por 24 horas, para permitir crescimento de diversos grupos bacterianos, como preconizado por Koneman et al. (2001). As colônias foram avaliadas de acordo com morfologia, tamanho, produção de pigmento e potencial de fermentação de carboidratos em cada meio. Todas as colônias fenotipicamente diferentes foram submetidas aos procedimentos de identificação presuntiva: coloração pelo método de Gram, prova da catalase e do hidróxido de potássio. Os testes específicos foram realizados para diferenciação de gêneros e identificação de espécies. Staphylococcus spp. isolados em AMVF, presuntivamente identificadas como cocos Gram-positivo, catalase-positivo, foram submetidos aos testes para identificação: coagulase em tubo, resistência à bacitracina, prova de Voges-Proskauer (VP), fermentação de maltose, redução de nitrato e produção de urease. Isolados de Streptococcus spp. foram repicados em ágar azida, incubados a $37^{\circ} \mathrm{C}$ por 24 horas e, posteriormente, submetidos à hidrólise de esculina e hipurato, prova da sensibilidade à optoquina e fermentação de carboidratos.

Colônias características de enterobactérias em AMC foram avaliadas quanto à fermentação de glicose e redução de nitrato, repicadas em ágar eosina azul de metileno (EMB), incubadas a $37^{\circ} \mathrm{C}$ por 24 horas e submetidas aos seguintes procedimentos para identificação das espécies: motilidade em ágar, repique em ágar três açúcares ferro (TSI) inclinado, produção de indol, fermentação de glicose com produção de gás, fermentação de outros carboidratos, hidrólise de gelatina, produção de urease e degradação de citrato e malonato, VP e vermelho de metila.

Para as colônias com características morfotintoriais de Bacillus spp., foram utilizados os testes para avaliação da hidrólise de hipurato e esculina, teste de Voges-Proskauer, hidrólise de gelatina, atividade de urease, fermentação de carboidratos e redução de nitrato (Koneman et al., 2001).

Foram isoladas 161 colônias distintas, de 33 espécies diferentes. Dentre estas, 18 não foram descritas até o presente momento em Stomoxys calcitrans, das quais, quatro pertenciam à família
Bacillaceae, sete à Enterobacteriaceae, seis à Micrococcaceae e uma à Streptococcaceae. Dentre as espécies da família Bacillaceae, Bacillus megaterium (1,2\%) e Bacillus subtilis $(3,1 \%)$ foram descritas apenas em $M$. domestica e Haematobia irritans, respectivamente (Greenberg, 1971). As espécies Bacillus alvei $(0,62 \%)$ e Bacillus coagulans $(2,5 \%)$ não haviam sido descritas em nenhum muscídeo até o presente momento.

Quanto à família Enterobacteriaceae, as espécies Citrobacter amalonaticus (0,62\%), Citrobacter diversus (1,2\%), Enterobacter cloacae (1,2\%), Klebsiella oxytoca (2,5\%) e Providencia stuartii $(0,62 \%)$ ainda não haviam sido identificadas em Muscidae, enquanto Enterobacter aerogenes $(0,62 \%)$ e Proteus vulgaris $(2,5 \%)$, antes deste estudo, só haviam sido citadas em outros muscídeos que não a mosca do estábulo (Greenberg, 1971; Förster et al., 2007).

Dentre as bactérias da família Micrococcaceae, Staphylococcus epidermidis $(0,62 \%)$ apresentava apenas uma citação, observada em Haematobia irritans por Stirrat et al. (1955) apud Greenberg (1971), enquanto as espécies Staphylococcus schleiferi coagulans (1,9\%), Staphylococcus equorum (1,2\%), Staphylococcus hyicus $(0,62 \%)$, Staphylococcus gallinarum (1,2\%) e Staphylococcus xylosus $(0,62 \%)$ não haviam sido citadas, até o momento, em nenhum estudo com muscídeos. A espécie Enterococcus faecalis $(0,62 \%)$ (Streptococcaceae) havia sido descrita somente nas moscas Hydrotaea dentipes e Musca domestica.

A primeira descrição dessas espécies bacterianas, em segmentos da mosca do estábulo, pode ser justificada pelo escasso número de trabalhos relacionados com microbiota bacteriana presente em Stomoxys calcitrans no Brasil, como também pela metodologia adotada neste estudo, em se tratando de isolamento bacteriano. Estudos anteriores relatam o isolamento de agentes bacterianos patogênicos em moscas, por meio da maceração e repique em um único meio enriquecido, habitualmente ágar sangue, o que favorece uma maior competição entre as espécies, fazendo, por vezes, com que uma espécie predomine (Brooks et al., 2000). O tipo de isolamento realizado neste estudo ofereceu condições distintas de crescimento para as espécies de microrganismos presentes nas 
amostras, permitindo maior acurácia na investigação microbiológica, o que contribuiu para a diversidade de espécies isoladas. Devem ser realizados estudos complementares para verificação da microbiota bacteriana, bem como do potencial patogênico dos agentes presentes na mosca do estábulo, como também em outras espécies de moscas.

Palavras-chave: mosca do estábulo, bactéria, identificação

\begin{abstract}
This study report the first description of bacterial species recovered from body segments of Stomoxys calcitrans collected in dairy farms from Rio de Janeiro State, Brazil. Eighteen out of 33 isolated and identified species were unknown in stable flies by the worldwide literature. Some of these species have the potential to develop diseases in man and other animals and some others have not been described yet as pathogenic agents.
\end{abstract}

Keywords: stable fly, bacteria, identification

\section{REFERÊNCIAS BIBLIOGRÁFICAS}

BANJO, A.D.; LAWAL, O.A.; ADEDUJI, O.O. Bacteria and fungi isolated from housefly (Musca domestica L.) larvae. Br. Vet. J., v.4, p.780-784, 2005.

BRAMLEY, A.J.; HILLERTON, J.E.; HIGGS, T.M. et al. The carriage of summer mastitis pathogens by muscid flies. Br. Vet. J., v.141, p.618-627, 1985.

BROOKS, G.F.; BUTEL, J.S.; MORSE, S.A. Jawetz, Melnick \& Adelber microbiologia médica. 20.ed. Rio de Janeiro: Guanabara Koogan, 2000. 524p.

CASTRO, B.G. Avaliação da microbiota bacteriana de segmentos da mosca Stomoxys calcitrans (Linnaeus, 1758) (Diptera: Muscidae) em propriedades rurais de municípios da Microrregião do Vale do Paraíba Fluminense. 2004. 62f. Dissertação (Mestrado) Universidade Federal Rural do Rio de Janeiro, Rio de Janeiro.

FOIL, L.D.; MEEK, C.L.; ADAMS, W.V. et al. Mechanical transmission of equine infectious anemia virus by deer fly (Chrisops flavidus) and stable fly (Stomoxys calcitrans). Am. J. Vet. Res., v.44, p.155-156, 1983.

FÖRSTER, M.; KLIMPEL, S.; MEHLHORN, H. et al. Pilot study on synanthropic flies (e.g. Musca, Sarcophaga, Calliphora, Fannia, Lucilia, Stomoxys) as vectors of pathogenic microorganisms. Parasitol. Res., v.101, p.243246, 2007.

FURMAN, D.P.; CATTS, E.P. Manual of Medical Entomology. 4.ed. Cambridge: Cambridge University, 1982. 207p.

GREENBERG, B. Flies and diseases. Ecology, classification and biotic association. Princeton: Princeton University, 1971. 856p.

HILlERTON, J.E; BRAMLEY, A.J. Carriage of Corynebacterium pyogenes by cattle nuisance flies Hydrotaea irritans (Fallen) and Musca autumnalis (De Geer). Vet. Parasitol., v.18, p.223-228, 1985.

KERR, C. Bloodsucking fly blamed for transmitting HIV. Lancet Inf. Dis., v.2, p.265, 2002.

KONEMAN, E.W.; JANDA, S.D.; SCHRECKENBERGER, W.M. et al. Diagnóstico microbiológico. 5.ed. Rio de Janeiro: MEDSI, 2001.

OLIVEIRA, V.C.; MELLO, R.P.; D’ALMEIDA, J.M. Dípteros muscóides como vetores mecânicos de ovos de helmintos em jardim zoológico, Brasil. Rev. Saude Publ., v.36, p.614620, 2002.

STIRRAT, J.H.; MCLINTOCK, J.; SCHWINDT, G.W. et al. Bacteria associated with wild and laboratory-reared horn flies, Siphona irritans (L.) (Diptera: Muscidae). J. Parasitol., v.41, p.398-406, 1955. 